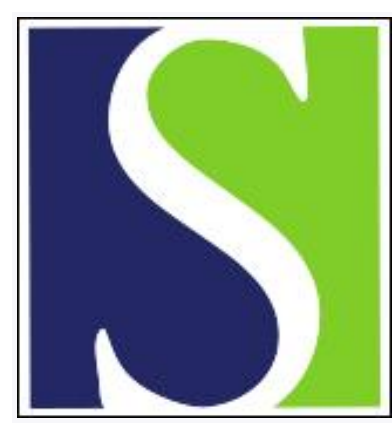

Scand J Work Environ Health 1987;13(4):358-362

https://doi.org/10.5271/sjweh.2027

Issue date: Aug 1987

Usefulness of blood parameters, especially viscosity, for the diagnosis and elucidation of pathogenic mechanisms of the hand-arm vibration syndrome.

by Okada A, Inaba R, Furuno T, Nohara S, Ariizumi M

Affiliation: Department of Public Health, School of Medicine, Kanazawa University, Japan.

This article in PubMed: www.ncbi.nlm.nih.gov/pubmed/3433039

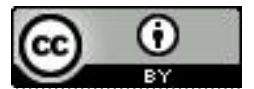




\title{
Usefulness of blood parameters, especially viscosity, for the diagnosis and elucidation of pathogenic mechanisms of the hand-arm vibration syndrome
}

\author{
by Akira Okada, MD, DMSc, Ryoichi Inaba, MD, DMSc, Toshio Furuno, MD, DMSc, \\ Seiichi Nohara, MD, DMSc, Makoto Ariizumi, MD, MDSc ${ }^{1}$
}

\begin{abstract}
OKADA A, INABA R, FURUNO T, NOHARA S, ARIIZUMI M. Usefulness of blood parameters, especially viscosity, for the diagnosis and elucidation of pathogenic mechanisms of the hand-arm vibration syndrome. Scand $J$ Work Environ Health 13 (1987) 358-362. In the present study it was found that, in vibrating-tool operators with Raynaud's phenomenon, whole blood viscosity was significantly higher than in operators without Raynaud's phenomenon at shear rates from 230 to $11.5 \mathrm{~s}^{-1}$. In addition rats were experimentally exposed to local vibration $(60 \mathrm{~Hz}, 5 \mathrm{~g})$ on their hind limbs for $4 \mathrm{~h} / \mathrm{d}$ for 30 or 90 d. In the case of 30-d exposure, the small arteries in the exposed site did not change. However, after exposure for $90 \mathrm{~d}$, disruption of the internal elastic lamina was observed in the small arteries. The disruption was followed by focal cell proliferation with regenerative formation of collagen and elastic fibers. The fibrocellular thickening of the intima was further augmented, and, in addition, a complete stenosis of the small lumen of the small artery was observed. Medial thickness did not show significant differences between the control and exposed groups for either exposure duration. The whole blood viscosity was significantly increased by the 90 - $\mathrm{d}$ but not by the 30 -d exposure. These results suggest that there are some relationships between the increase in whole blood viscosity and the intimal thickening of some small arteries in the exposed site.
\end{abstract}

Key terms: blood viscosity, intimal thickening, local vibration, Raynaud's phenomenon, vibration syndrome.

To clarify the mechanism of the occurrence of Raynaud's phenomenon, which is a characteristic symptom of the hand-arm vibration syndrome, our department has studied the occurrence of intimal thickening in the peripheral artery of the rat at the site of local chronic exposure to vibration in the rat. The present study aimed at evaluating the possible relationship between histological changes in the peripheral arteries and blood viscosity on the basis of data from a field survey and an animal experiment.

\section{Material and methods}

\section{Measurement of blood viscosity \\ in the field survey}

The study group consisted of 11 workers with and 18 without Raynaud's phenomenon. All the subjects regularly worked with chain saws. The two groups were similar with respect to age and the length of use of vibrating tools. Whole blood and plasma viscosity, plasma cyclic AMP (adenosin-monophosphate), and GMP (guanosin-monophosphate) were determined. The whole blood and plasma viscosity were measured at $37^{\circ} \mathrm{C}$ with a Wells-Brookfield cone-plate microviscometer (model LVT) at the following five shear rates: 230 ,

1 Department of Public Health, School of Medicine, Kanazawa University, Kanazawa, Japan.

Reprint requests to: Professor A Okada, Kanazawa University, School of Medicine, Department of Public Health, 13-1 Takara-machi, Kanazawa, 920 Japan.
$115,46,23$, and $11.5 \mathrm{~s}^{-1}$. The plasma cyclic AMP and cyclic GMP levels were determined with the radioimmunologic method developed by Honma et al (3).

\section{Experimental study}

Twenty male Wistar rats, initially weighing $230-250 \mathrm{~g}$, were used. Each group consisted of five rats. The rats were exposed to local vibration on their hind legs for $4 \mathrm{~h} / \mathrm{d}$ for either 30 or $90 \mathrm{~d}$. The apparatus used for the vibration exposure consisted of an electromagnetic shaker with a shaking power of $7.5 \mathrm{~kg}$ (vibration frequency range $5-5000 \mathrm{~Hz}$ ) coupled to an amplifier, a function oscillator, and a vibration meter. The animals were placed in individual mesh cages, in the prone position. The hind legs were outside the cage, their plantar surfaces horizontally fixed to the vibrating plate with doublesided adhesive tape, so that the vibration would be transmitted only to the hind legs. The part of the cage containing the rest of the rat body was fixed on a nonvibrating plate separated from the shaker. The hind legs were exposed to vertical sinusoidal vibration with a frequency of $60 \mathrm{~Hz}$ under a constant acceleration of $5 \mathrm{~g}(50 \mathrm{~m} \cdot \mathrm{s} \cdot 2)$. Before the experiments, the rats were trained for one week to accept this exposure. The control group, in each experiment, was kept in wire mesh cages like the ones used for the exposed group. The control animal cages were placed near the operating electromagnetic shaker during the exposure experiment so that the exposure to noise would be equal in both groups. The temperature of the animal room was kept at $20 \pm 2^{\circ} \mathrm{C}$, and a 12-h "light-dark cycle" was maintained. Food and water were provided ad libitum before the start of the exposure experiment. Eighteen hours after the last exposure, samples for electron microscopic examination were obtained from the dorsal side of the foot, and blood was then collected after decapitation.

Whole blood viscosity was measured in this study with a Wells-Brookfield cone-plate microviscometer at the shear rates of 230 and $115 \mathrm{~s}^{-1}$. A microscopic examination was made 
Table 1. Whole blood viscosity, plasma viscosity, and hematocrit measured at $37^{\circ} \mathrm{C}$ in the vibration-exposed workers with and without Raynaud's phenomenon.

\begin{tabular}{|c|c|c|c|c|c|c|c|c|c|c|c|c|c|c|c|c|c|c|c|c|c|c|}
\hline & \multicolumn{20}{|c|}{ Viscosity (centipoise) } & \multirow{3}{*}{\multicolumn{2}{|c|}{$\begin{array}{c}\text { Hema- } \\
\text { tocrit } \\
(\%)\end{array}$}} \\
\hline & \multicolumn{10}{|c|}{ Whole Blood } & \multicolumn{10}{|c|}{ Plasma } & & \\
\hline & \multicolumn{2}{|c|}{$230^{\mathrm{a}}$} & \multicolumn{2}{|c|}{$115^{a}$} & \multicolumn{2}{|c|}{$46^{a}$} & \multicolumn{2}{|c|}{$23^{a}$} & \multicolumn{2}{|c|}{$11.5^{\mathrm{a}}$} & \multicolumn{2}{|c|}{$230^{a}$} & \multicolumn{2}{|c|}{$115^{a}$} & \multicolumn{2}{|c|}{$46^{a}$} & \multicolumn{2}{|c|}{$23^{a}$} & \multicolumn{2}{|c|}{$11.5^{\mathrm{a}}$} & & \\
\hline & Mean & SD & Mean & SD & Mean & $S D$ & Mean & SD & Mean & SD & Mean & SD & Mean & SD & Mean & SD & Mean & $S D$ & Mean & SD & Mean & SD \\
\hline $\begin{array}{l}\text { Group without } \\
\text { Raynaud's } \\
\text { phenomenon } \\
(\mathrm{N}=18)\end{array}$ & 4.59 & 0.60 & 5.19 & 0.81 & 6.76 & 1.21 & 7.91 & 1.45 & 8.18 & 1.71 & 1.62 & 0.26 & 1.71 & 0.38 & 2.06 & 0.53 & 2.15 & 0.60 & 2.61 & 1.02 & 42.6 & 4.3 \\
\hline $\begin{array}{l}\text { Group with } \\
\text { Aaynaud's } \\
\text { phenomenon } \\
(\mathrm{N}=11)\end{array}$ & $5.32^{\star *}$ & 0.65 & $6.36^{* *}$ & 0.96 & $8.25^{\star *}$ & 1.10 & $9.85^{* *}$ & * 1.74 & $10.29^{*}$ & 2.57 & 1.71 & 0.26 & 1.76 & 0.40 & 2.20 & 0.58 & 2.21 & 0.60 & 2.74 & 0.87 & 44.8 & 4.2 \\
\hline
\end{tabular}

of cross-sections of formalin-fixed specimens obtained from the foot, $1.5 \mathrm{~cm}$ distal of the ankle, and stained with hematoxylin eosin and Elastica-Van Gieson. According to Suwa's histometrical method (2), cross-sections of arteries were reduced to the state in which the internal elastic lamina was perfectly stretched, and the thickness of the media (D) and the radius $(R)$ could be measured. Samples for the electron microscopic examination were fixed with $2.5 \%$ glutaraldehyde for $1 \mathrm{~h}$ and postfixed in $2 \%$ Osmium tetroxide for 1 $\mathrm{h}$, both of which were buffered with $0.1 \mathrm{M}$ sodium cacodylate at $\mathrm{pH}$ 7.4. After dehydration, the samples were embedded in Epon 812-filled gelatin capsules. Thin sections were obtained with an LKB Ultrotome, stained with uranyl acetate and lead citrate, and observed in a Hitachi $\mathrm{H}-500$ electron microscope operating at $75 \mathrm{kV}$.

\section{Results and discussion}

Table 1 shows the whole blood and plasma viscosity of the vibrating tool operators with and without Raynaud's phenomenon. In the group with Raynaud's phenomenon, the whole blood viscosity was statistically significantly higher at each shear rate in comparison with that of the group without Raynaud's phenomenon. No significant differences in plasma viscosity were observed between the two groups. These results indicate that whole blood viscosity may play an important role in the appearance of the vascular symptom or signs of the hand-arm vibration syndrome. In addition, the data imply that it is possible to discriminate between a group with Raynaud's phenomenon and a group without it by measuring whole blood viscosity. The plasma cyclic AMP and GMP levels showed no group differences with statistical significance.

Several investigators have studied the effects of hand-arm vibration on blood components (7) (table 2 ), and there are indications that many blood components may be affected by hand-arm vibration. However, some of the reports lack pertinent statistical tests.

In the present work $30-\mathrm{d}$ exposure did not cause any histological changes in the small arteries at the exposed site. However, after $90 \mathrm{~d}$, there were changes in the small arteries of the hind leg of the rats with the following findings: disruption of the internal elastic lamina, focal cell proliferation, and regenerative for-
Table 2. Reports relating to the effects of hand-arm vibration on blood components.

\begin{tabular}{|c|c|c|c|}
\hline \multirow{3}{*}{$\begin{array}{l}\text { Blood components } \\
\text { Serum noradrenaline } \\
\text { Serum noradrenaline } \\
\text { Serum haptoglobin and } \\
\text { immunoglobulin } \mathrm{M} \\
\text { Erythrocyte osmotic }\end{array}$} & \multirow{2}{*}{$\begin{array}{l}\text { Effect } \\
\begin{array}{l}\text { Increase } \\
\text { Increase }\end{array}\end{array}$} & \multicolumn{2}{|c|}{$\begin{array}{l}\text { Authors and year } \\
\text { of publication }\end{array}$} \\
\hline & & $\begin{array}{l}\text { Lubanska et al } \\
\text { Johansen et al }\end{array}$ & $\begin{array}{l}(1965) \\
(1977)\end{array}$ \\
\hline & Increase & Okada et al & (1971) \\
\hline fragility & Decrease & Habu et al & (1978) \\
\hline fragility & & Ikeda et al & (1979) \\
\hline $\begin{array}{l}\text { Red cell deformation } \\
\text { Platelet aggregation }\end{array}$ & $\begin{array}{l}\text { Decrease } \\
\text { Increase }\end{array}$ & $\begin{array}{l}\text { Dodds } \\
\text { lkehata et al }\end{array}$ & $\begin{array}{l}(1979) \\
(1980)\end{array}$ \\
\hline $\begin{array}{l}\text { Platelet aggregation } \\
\text { Serum sarcoplasmic }\end{array}$ & Increase & Kanamori et al & (1982) \\
\hline $\begin{array}{l}\text { creatine phosphokinase, } \\
\text { lactate dehydrogenase) }\end{array}$ & Increase & Kasamatsu et al & (1980) \\
\hline $\begin{array}{l}\text { Serum sarcoplasmic } \\
\text { enzyme activity (aldolase, } \\
\text { creatine phosphokinase, }\end{array}$ & & & \\
\hline lactate dehydrogenase) & Increase & Okada et al (6) & (1985) \\
\hline Blood beta-thromboglobulin & Incr & Kan & (1982) \\
\hline Fibrinolysis system activit & $\begin{array}{l}\text { Increase } \\
\text { Increase }\end{array}$ & $\begin{array}{l}\text { Kondo et al (5) } \\
\text { Kondo et al (5) }\end{array}$ & $\begin{array}{l}(1984) \\
(1984)\end{array}$ \\
\hline
\end{tabular}

mation of collagen and elastic fibers (figure 1), thrombofixation (one case, figure 2), fibrocellular thickening of the intima (figure 3), and complete stenosis (figure 4). Electron microscopically (figure 5), the fibrocellular thickening of the intima was seen to be caused by a proliferation of arterial smooth muscle cells from the media together with a formation of collagen and elastic fibers.

According to the hypothesis recently presented by Ross et al (8), atherosclerotic lesions may arise as a result of injury to the endothelium and result in desquamation followed by the adherence, aggregation, and release of platelets at the site of the injury. During the process of platelet release, a mitogenic factor, secreted from the platelets, gains entry into the artery wall and causes focal proliferation of intimal smooth muscle cells. If the injury is a single event, the lesions may heal and regress, a slightly thickened intima being the result. However, if the injury to the endothelium is repeated or chronic, the initial thickening may be pronounced. Figure 6 describes a hypothesis for the mechanism of vibration-induced intimal thickening of 


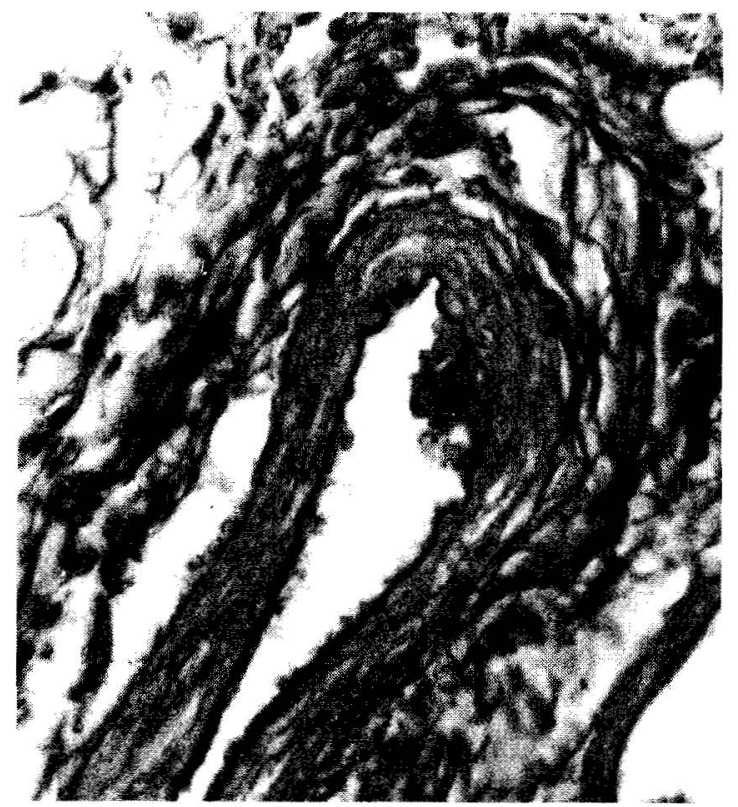

Figure 1. Light micrograph of a section through a small artery of a hind leg of a rat after local vibration exposure $4 \mathrm{~h} / \mathrm{d}$ for $90 \mathrm{~d}$. Disruption of the internal elastic lamina and focal cell proliferation with formation of collagen and elastic fibers. (Elastica-Van Gieson stain, X 330)

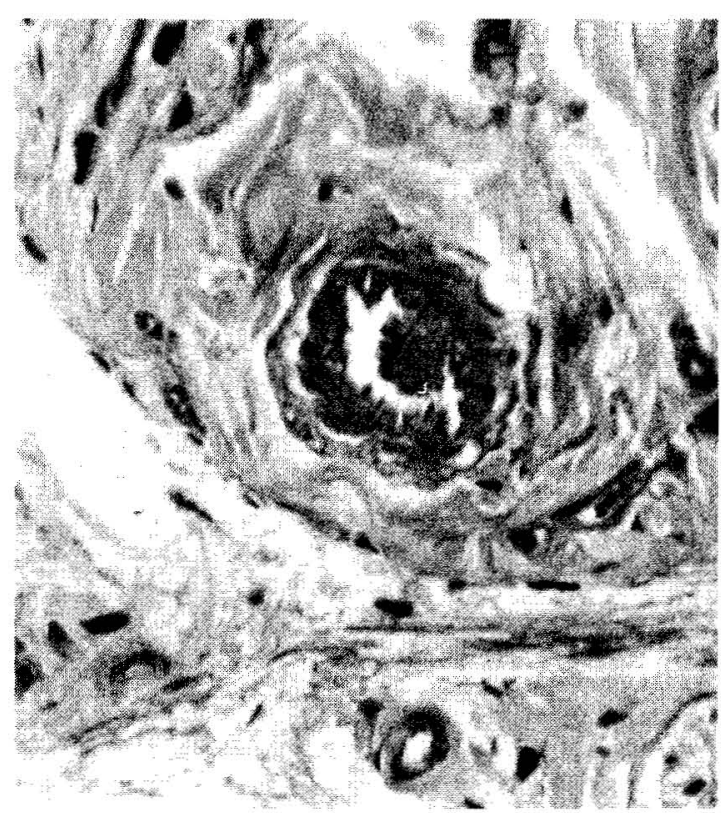

Figure 2. Light micrograph of a section through a small artery of a hind leg of a rat after local vibration exposure $4 \mathrm{~h} / \mathrm{d}$ for $90 \mathrm{~d}$. A fresh fibrin thrombus in the lumen of the small artery. (Hematoxylin-eosin stain, $X 330$ )

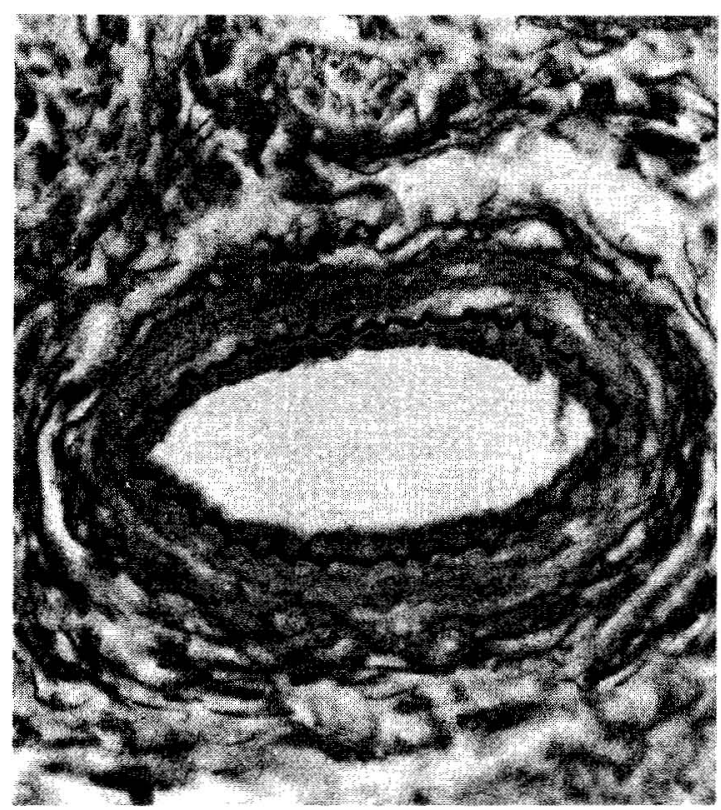

Figure 3. Light micrograph of a section through a small artery of a hind leg of a rat after local vibration exposure $4 \mathrm{~h} / \mathrm{d}$ for $90 \mathrm{~d}$. Mild fibrocellular thickening of intima. (Elastica-Van Gieson stain, X 330)

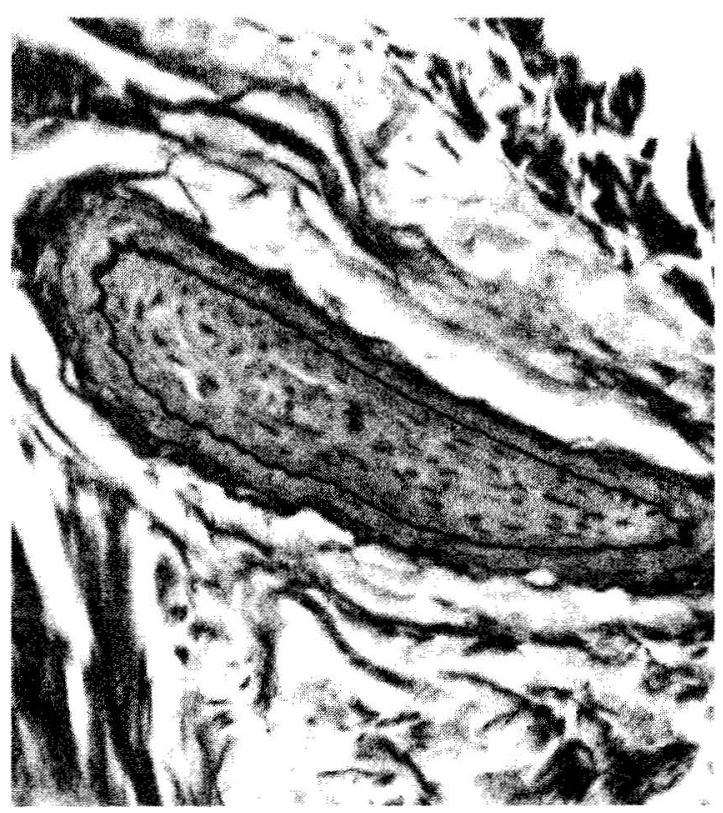

Figure 4. Light micrograph of a section through a smal! artery of a hind leg of a rat after local vibration exposure $4 \mathrm{~h} / \mathrm{d}$ for $90 \mathrm{~d}$. Severe intimal thickening and complete stenosis of the lumen. (Elastica-Van Gieson stain, X 330) 


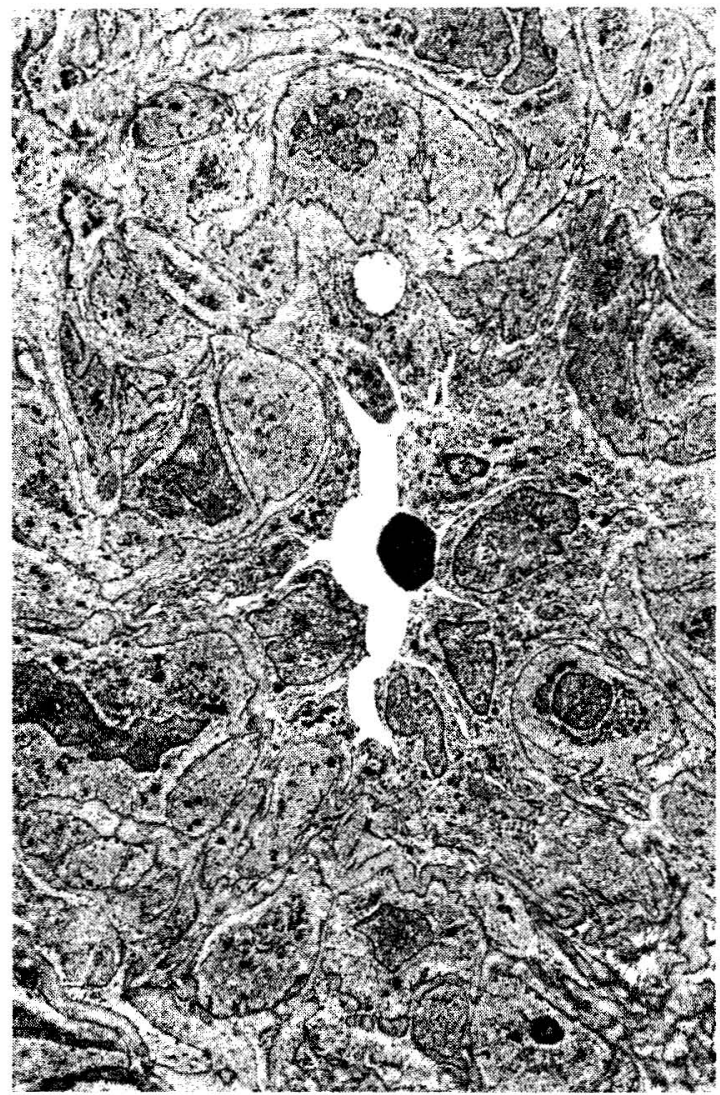

Figure 5. Electron micrograph from a small artery of a hind leg of a rat after local vibration exposure $4 \mathrm{~h} / \mathrm{d}$ for $90 \mathrm{~d}$. Proliferation of arterial smooth muscle cells from the media associated with formation of collagen and elastic fibers. (X 4500)

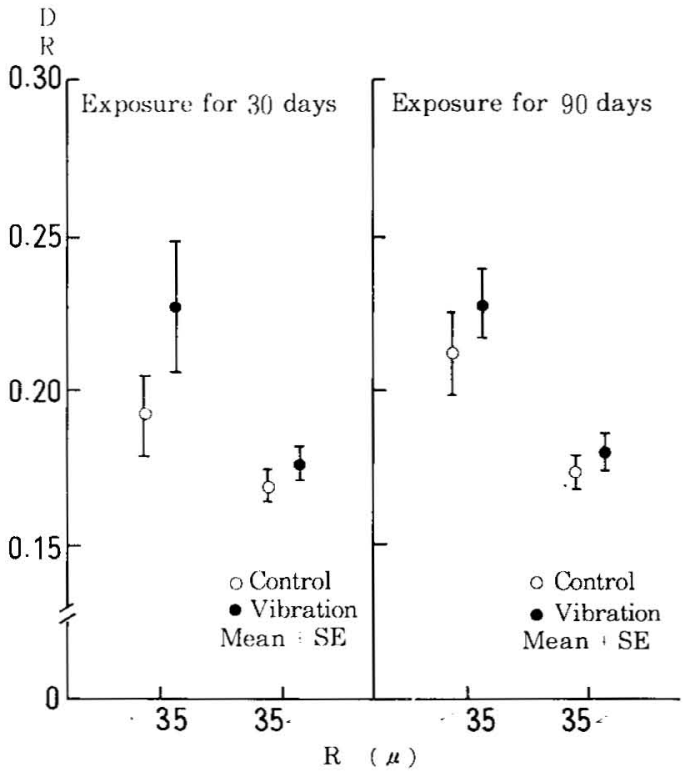

Figure 7. Changes in medial thickness (represented as D/R) in the arteries of hind legs of rats exposed to vibration. $(\mathrm{D}=$ media, $\mathrm{R}=$ radius $)$

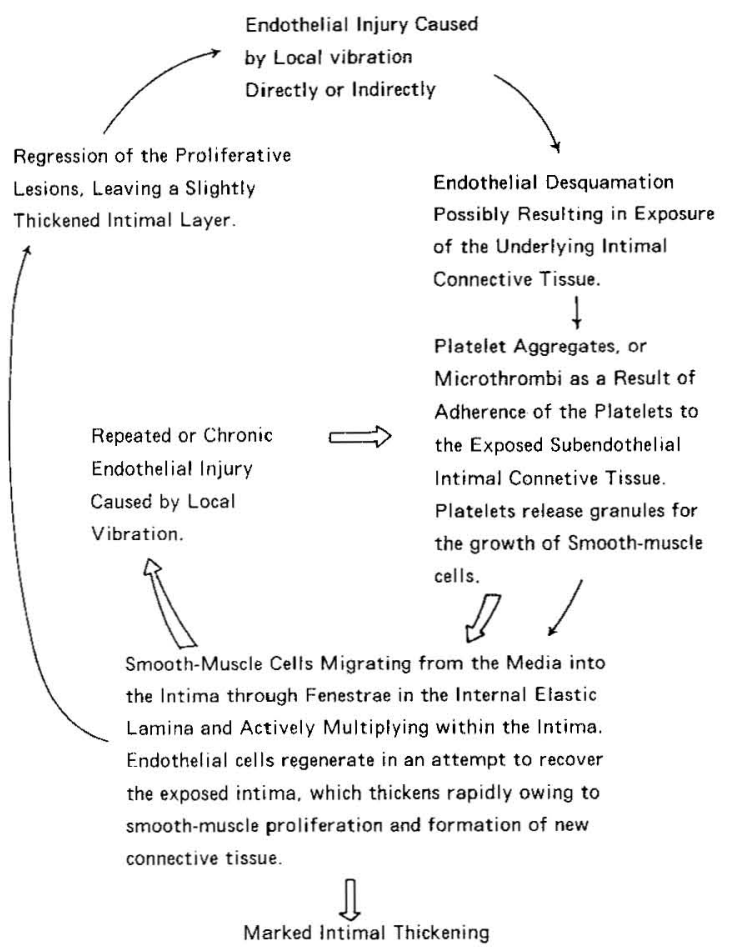

Figure 6. Hypothesis of the mechanism of intimal thickening in small arteries as induced by local vibration exposure.

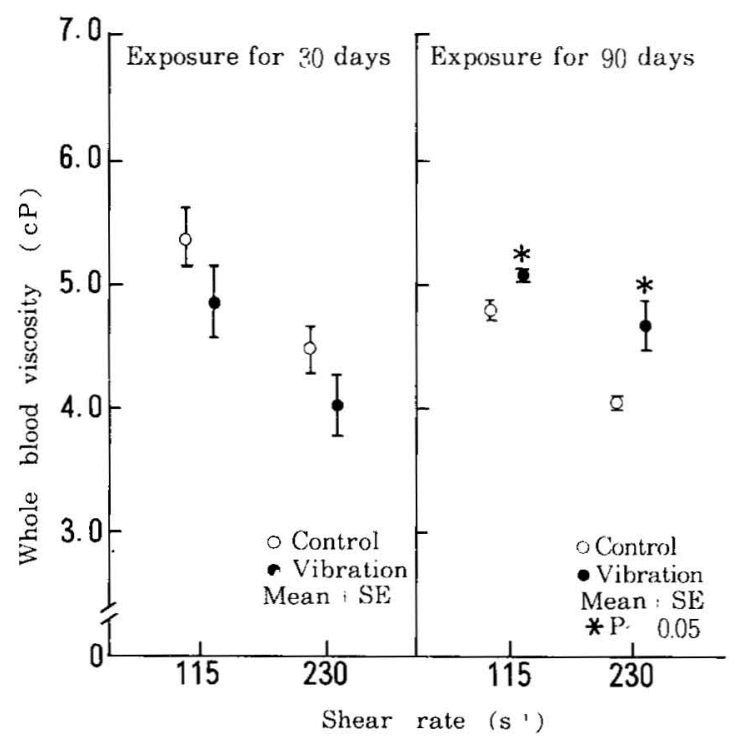

Figure 8. Whole blood viscosity, at the shear rates of $115 \mathrm{~s}^{-1}$ and $230 \mathrm{~s}^{-1}$, of rats exposed to local vibration. ( $C P=$ centipoise) 


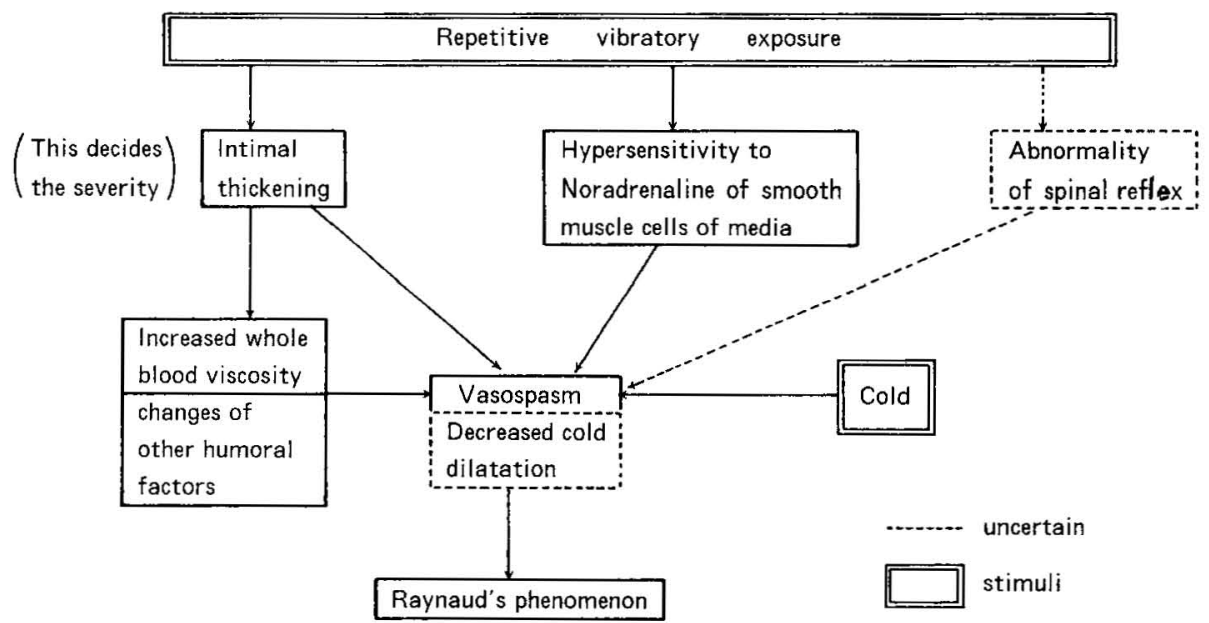

Figure 9. Hypothesis of the pathogenetic mechanism of Raynaud's phenomenon induced by local vibration exposure.

small arteries; the hypothesis is supported by the finding of a fresh fibrin thrombus after 90-d exposure in the present experiment.

Azuma et al (1) reported that, after vibratory stimulation, the responsiveness of arterial smooth muscle to noradrenaline markedly increased, and the vasoconstrictive activity of noradrenaline was also markedly elevated. Kobori (4) observed that an injection of methoxamine hydrochloride (a vasoconstrictive agent) caused endothelial injury in the mesenteric artery. It is proposed by us that the sensitivity of the arterial vessels to noradrenaline increases after vibration exposure, and the artery constricts or goes into spasm, resulting in endothelial injury. The hypothetical mechanism of repeated or chronic endothelial injury by vibration, as causing an intimal thickening, receives support from the present results.

Vibration-induced medial thickening of the artery has been paid greater attention than intimal thickening (9). In the present study there was no statistically significant difference in medial thickness between the control and exposed groups with either exposure duration (figure 7). Furthermore, Furuyama (2) reported on a statistically significant correlation between the thickness of the media in the mesenteric and femoral arteries and blood pressure, a finding which calls for caution when biopsy data from vibration-exposed workers are being interpreted.

Whole blood viscosity at shear rates of 115 and 230 $\mathrm{s}^{-1}$ did not differ statistically significantly between the control and exposed groups after $30 \mathrm{~d}$ of exposure (figure 8). After $90 \mathrm{~d}$, however, the exposed group showed a significantly higher blood viscosity at each shear rate as compared with the control group. These results indicate some relationship between the increase in whole blood viscosity and the intimal thickening of some small arteries in the exposed site. In addition, whole blood viscosity is implied as a useful parameter in the diagnosis of the hand-arm vibration syndrome.

A hypothesis for the pathogenic mechanism of Raynaud's phenomenon is described in figure 9. On the basis of the findings in the present study, it is suggested that some relationship exists between intimal thickening of small arteries and the occurrence and severity of Raynaud's phenomenon.

\section{References}

1. Azuma T, Ohhashi T, Sakaguchi M. An approach to the pathogenesis of "white finger" induced by vibratory stimulation: Acute but sustained changes in vascular responsiveness of canine hind limb to noradrenaline. Cardiovasc Res 14 (1980) 725-730.

2. Furuyama M. Histometrical investigations of arteries in reference to arterial hypertension. Tohoku J Exp Med 76 (1962) $388-414$.

3. Honma M, Satoh T, Takezawa J, Ui M. An ultrasensitive method for the simultaneous determination of cyclic AMP and cyclic GMP in small-volume samples from blood and tissue. Biochem Med 18 (1977) 257-273.

4. Kobori K. Pathomorphological study on experimental arterial contraction (spasm) in rats. J Jpn Coll Angiol 16 (1976) 613-623.

5. Kondo $\mathrm{M}$, Agishi $\mathrm{H}$, Ide $\mathrm{H}$, Asanuma $\mathrm{Y}$, Fujiya S, Nishihara H, Sakai H. Coagulation and fibrinolysis system in patients with vibration syndrome. Jpn J Ind Health 26 (1984) 777.

6. Okada A, Okuda H, Inaba R, Ariizumi M. Influence of local vibration on plasma creatine phosphokinase (CPK) activity. Br J Ind Med 42 (1985) 678-681.

7. Okada A, Suzuki K, ed. Vibration hazards: Research and clinical practice. Shinohara Shuppan, Tokyo 1982.

8. Ross R, Glomet J, Harker L. Response to injury and atherogenesis. Am J Pathol 86 (1977) 675-684.

9. Takeuchi T, Imanishi H. Histopathologic observations in finger biopsy from thirty patients with Raynaud's Phenomenon of occupational origin. J Kumamoto Med Soc 58 (1984) $56-70$. 